
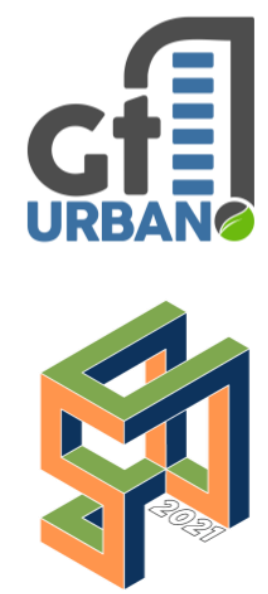

SINGEURB

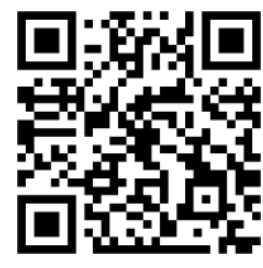

Como citar:

RAMOS, Larissa

Leticia Andara;

PASSAMANI,

Amanda Jeveaux;

JESUS, Luciana

Aparecida Netto de;

CONDE, Karla

Moreira.

Sociabilidade, usos e atividades em praças: avaliação a partir da ferramenta QualificaURB. In: III SIMPÓSIO

NACIONAL DE

GESTÃO E

ENGENHARIA

URBANA:

SINGEURB, 2021,

Maceió. Anais...

Porto Alegre:

ANTAC, 2021. p.281-

289.

Disponível em:

https://eventos.antac.

org.br/index.php/sin

geurb/issue/view/14
Artigo Compacto

\section{Sociabilidade, usos e atividades em praças: avaliar a partir da ferramenta QualificaURB}

\author{
Sociability, uses and activties of squares: \\ evaluation from the QualificaURB tool
}

Larissa Leticia Andara Ramos, Universidade Vila Velha (UVV),

larissa.ramos@uvv.br

Amanda Jeveaux Passamani, Universidade Vila Velha (UVV), amandajeveauxp@gmail.com

Luciana Aparecida Netto de Jesus, Universidade Federal do Espírito Santo (UFES), luciana.a.jesus@ufes.br

Karla Moreira Conde, Universidade Federal do Espírito Santo (UFES), karlamconde@gmail.com

\section{RESUMO}

Espaços livres públicos são fundamentais para a sociabilidade e a vitalidade urbana, entretanto, nota-se carência de elementos que contribuem para a função social desses espaços. Diante da escassez de ferramentas direcionadas a avaliação de espaços público, a pesquisa analisa a qualidade socioambiental de praças, a partir da aplicação de indicadores de sociabilidade, usos e atividades presentes na ferramenta QualificaURB. Trata-se de uma pesquisa aplicada, desenvolvida dentro de uma rede colaborativa entre duas universidades, com recorte espacial de análise as praças da Grande Cobilândia, Vila Velha-ES. A ferramenta QualificaURB, desenvolvida pelo Grupo de Pesquisa "Paisagem Urbana e Inclusão", é organizada em 4 categorias: Proteção e Segurança; Conforto e Imagem; Acessos e Conexões; e Sociabilidade, Usos e Atividades, que recebem classificações variando de "insuficiente", "regular", "bom" à "ótimo". Tendo como ênfase a categoria "Sociabilidade, Usos e Atividades", que analisa equipamentos e atividades que favoreçam a sociabilidade de praças, $60 \%$ delas receberam classificação entre "insuficiente" e "regular" e outras 40\% atingiram classificação "ótimo" e "bom". Tal cenário evidencia um panorama diversificado entre os usos das praças, resultando em espaços não convidativos à sociabilidade. As avaliações contribuem, ainda, na identificação de vulnerabilidades e de aspectos passíveis de melhorias que ressignifiquem a função social das praças.

Palavras-chave: Avaliação, Praças, Espaços Livres Públicos, Qualidade Urbana.

\section{ABSTRACT}

Publics open spaces are fundamental for urban sociability and vitality; however, there is a lack of elements that contribute to the social function of these spaces. Given the scarcity of tools aimed at the assessment of public spaces, the research presents the results of the analyzes and analyzes the socio-environmental quality of aspects that qualify as squares, based on the application of indicators of sociability, uses and activities, present in the QualificaURB tool. This is an applied research, developed within a collaborative network 
between two universities, with an analytical approach to the squares of Grande Cobilândia, Vila Velha-ES. The QualificaURB tool, developed by the "Paisagem Urbana e Inclusão" Research Group, is organized into 4 categories: Protection and Security; Comfort and Image; Accesses and Connections; and Sociability, Uses and Activities, which receive ratings ranging from "insufficient", "regular", "good" to "excellent". Regarding the category "Sociability, Uses and Activities" - which analyzes the attractions, equipment and activities that favor greater sociability in the squares $-60 \%$ of them were rated between "insufficient" and "regular" and 40\% achieved a "great" rating and/or "good". This scenario shows a diversified panorama between the uses of the squares, resulting in uninviting spaces for sociability. The assessments also contribute to the identification of vulnerabilities and aspects that can be improved that re-signify the social function of the squares.

Keywords: Evaluation, Squares, Public Open Spaces, Urban Quality.

\section{INTRODUÇÃO}

No Brasil, as ideologias de planejamento e o processo de urbanização promoveram o uso dos automóveis, negligenciando o pedestre e a função social do espaço público como local de encontro (GEHL, 2014). Queiroga (2011) ressalta que são nos espaços livres que a vida pública tem seu maior suporte, constituídos por locais que apresentam acessibilidade, diversidade e pluralidade. Dentre esses, as praças ganham destaque por seu papel ambiental, mas sobretudo social, através dos estímulos às práticas de lazer, recreação e esportivas. São espaços que contribuem para a qualidade urbana, favorecem a vitalidade, o enriquecimento sociocultural, o exercício da cidadania e a constituição da esfera pública (MACEDO et al, 2018).

Considerando o potencial dos espaços públicos como meio fundamental para a realização de trocas sociais, percebe-se a relevância de estudos que busquem avaliar aspectos que contribuem para a apropriação do espaço público da praça, como a qualidade e quantidade de equipamentos públicos e atividades existentes, bem como identifiquem falhas que não favoreçam a sociabilidade $e$, consequentemente, afastam as pessoas de utilizarem e permanecerem no espaço.

Neste sentido, a partir da aplicação da ferramenta de avaliação socioambiental dos espaços públicos, desenvolvida pelo Grupo de Pesquisa "Paisagem urbana e Inclusão" busca-se neste artigo apresentar a aplicação e avaliação da categoria "Sociabilidade, Usos e Atividades" considerando como recorte espacial as praças da Grande Cobilândia, município de Vila Velha, estado do Espirito Santo.

A ferramenta em questão visa suprir a carência de metodologias avaliativas com foco em praças e estrutura-se em quatro categorias de análises: "Proteção e Segurança", "Conforto e Imagem"; "Acessos e Conexões"; e "Sociabilidade, Usos e Atividade". Cada uma delas é subdividida em atributos e indicadores que avaliam a qualidade socioambiental dos espaços públicos. Este artigo, porém, traz como enfoque a aplicação da categoria "Sociabilidade, Usos e Atividades", que observa as apropriações, equipamentos e atividades que atraem, motivam e dão vida aos espaços públicos, influenciando diretamente nas condições de apropriação e vivência nas praças. 


\section{FERRAMENTA DE AVALIAÇÃO QUALIFICAURB}

A ferramenta QualificaURB foi desenvolvida com base no Índice de Caminhabilidade - iCam (Brasil ITDP, 2019), mediante adequações para o espaço público da praça, somado aos conceitos de Whyte (2009), presente no Guia do Espaço Público (HEEMANN; SANTIAGO, 2015) e de uma robusta revisão de literatura.

Na ferramenta, os parâmetros de análise estão organizados em 04 (quatro) categorias: "Proteção e Segurança", "Conforto e Imagem", "Acessos e Conexões" e "Usos e Atividades", subdivididas em atributos e indicadores, para, assim, assegurar a aplicabilidade e posterior comparação de resultados. As categorias são subdivididas em 11 atributos, que são, por sua vez, compostos por 24 indicadores. Cada indicador apresenta parâmetros de análise que permite atribuir uma pontuação unitária de acordo com o desempenho do indicador analisado.

Conforme ilustrado no Quadro 1, a categoria "Sociabilidade, Usos e Atividades" é dividida em três atributos: "espaços para brincar", "atrações" e "equipamentos e atividades". O primeiro deles avalia os espaços infantis da praça, considerando a localização, o material do piso, o material dos brinquedos e o estado de conservação. Considera-se também atividades que incluem os idosos, além da presença de equipamentos comunitários e do uso do solo do entorno. O segundo atributo "Equipamentos e Atividades" observa as atividades comerciais e de serviços realizadas na praça, bem como as apropriações comunitárias.

Quadro 1 - Atributos e Indicadores pertencentes à "Sociabilidade, Usos e Atividades"

\begin{tabular}{|c|c|c|c|}
\hline CATEGORIA & ATRIBUTOS & & INDICADORES \\
\hline \multirow{9}{*}{$\begin{array}{c}\text { D. } \\
\text { Sociabilidade } \\
\text {, Usos e } \\
\text { Atividades }\end{array}$} & \multirow{7}{*}{ D.1. Atração } & \multirow{4}{*}{$\begin{array}{l}\text { D.1.1. Espaços } \\
\text { para brincar }\end{array}$} & Localização do Espaço para Brincar \\
\hline & & & Material do Piso da Área Infantil \\
\hline & & & Material dos Brinquedos Infantis \\
\hline & & & Estado de Conservação dos Brinquedos \\
\hline & & \multicolumn{2}{|c|}{ D.1.2. Equipamentos comunitários } \\
\hline & & \multicolumn{2}{|c|}{ D.1.3. Atividades que incluem idosos } \\
\hline & & \multicolumn{2}{|l|}{ D.1.4. Uso do Solo } \\
\hline & \multirow{2}{*}{$\begin{array}{c}\text { D.2 Equipamentos } \\
\text { e Atividades }\end{array}$} & \multicolumn{2}{|c|}{ D.2.1 Equipamentos fixos e serviços dentro da praça } \\
\hline & & \multicolumn{2}{|c|}{ D.2.2. Atividades apropriações comunitárias (I dentidade sociocultural) } \\
\hline
\end{tabular}

Fonte: Os autores

Para cada indicador, a ferramenta define parâmetros de análise, com critérios de pontuação, sendo atribuída uma nota de 0 (zero) a 3 (três) para cada indicador, que correspondem, respectivamente, ao nível "insuficiente" e "ótimo" dos critérios, permitindo assim uma classificação por praça, mas também por categoria, critério e indicador. A Tabela 1 demonstra como a pontuação e classificação é atribuída.

Tabela 1 - Classificação e pontuação atribuída

\begin{tabular}{|c|c|c|c|}
\hline Pontuação $\mathbf{0}$ até $\mathbf{0 , 7 5}$ & Pontuação $\mathbf{0 , 7 6}$ até $\mathbf{1 , 5}$ & Pontuação $\mathbf{1 , 5 1}$ até $\mathbf{2 , 2 5}$ & Pontuação $\mathbf{2 , 2 6}$ até $\mathbf{3 , 0}$ \\
\hline Insuficiente & Regular & Bom & Ótimo \\
\hline
\end{tabular}

Fonte: Os autores 


\section{REGIONAL GRANDE COBILÂNDIA}

O município de Vila Velha é dividido em cinco regiões administrativas (Figura 1A). A Grande Cobilândia (evidenciada na Figura 1 em lilás) possui destaque tendo em vista seu contexto de vulnerabilidade social e ambiental, com uma população de 65.970 habitantes (IBGE, 2010). Observa-se, conforme ilustrado na Figura 1B, que quase toda a extensão territorial da Grande Cobilândia é cortada por canais e ocupada por áreas alagáveis, representando um contexto de vulnerabilidade socioambiental uma vez que a regional registra altos índices de alagamentos.

Figura 1 - Regional Grande Cobilândia
A) Localização da Regional.
B) Mapa físico-ambiental da Regional
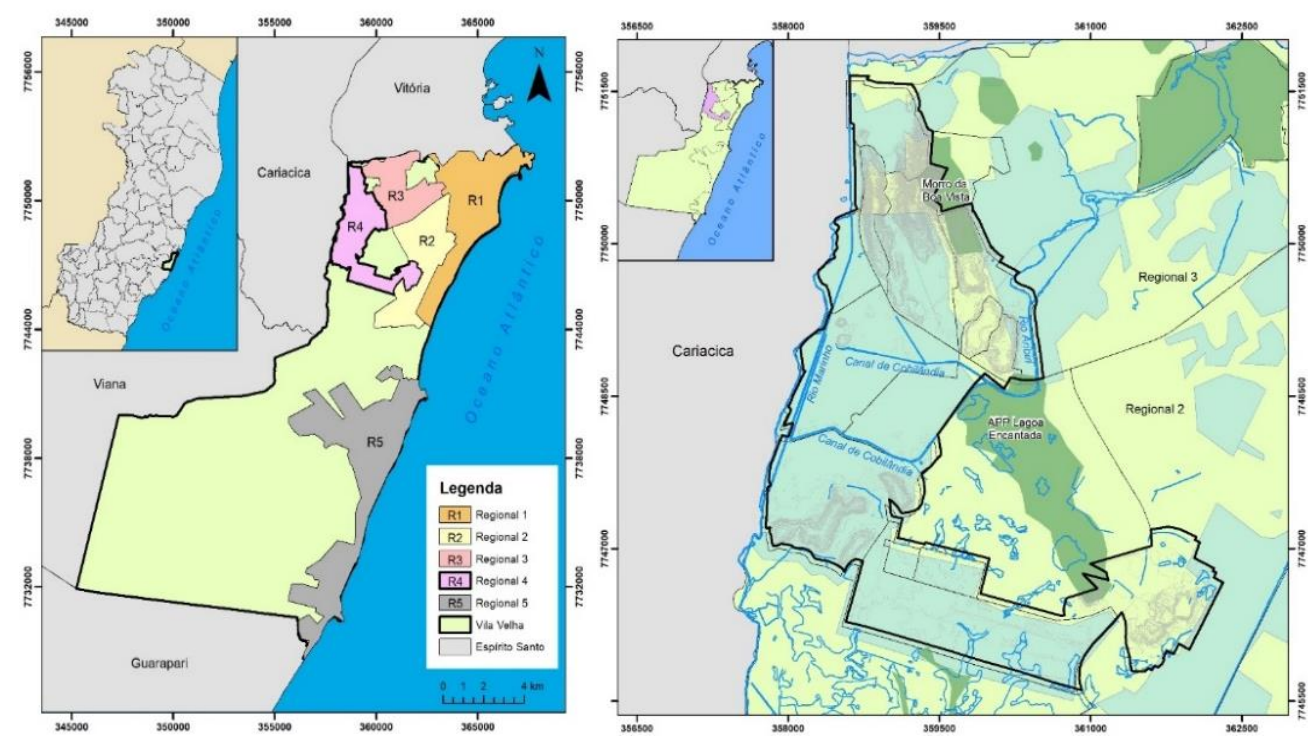

Mapa fisico-ambiental Regional IV: Grande Cobilândia

Fonte: Os autores (2021)

Figura 2 - Mapeamento das praças da Regional Grande Cobilândia

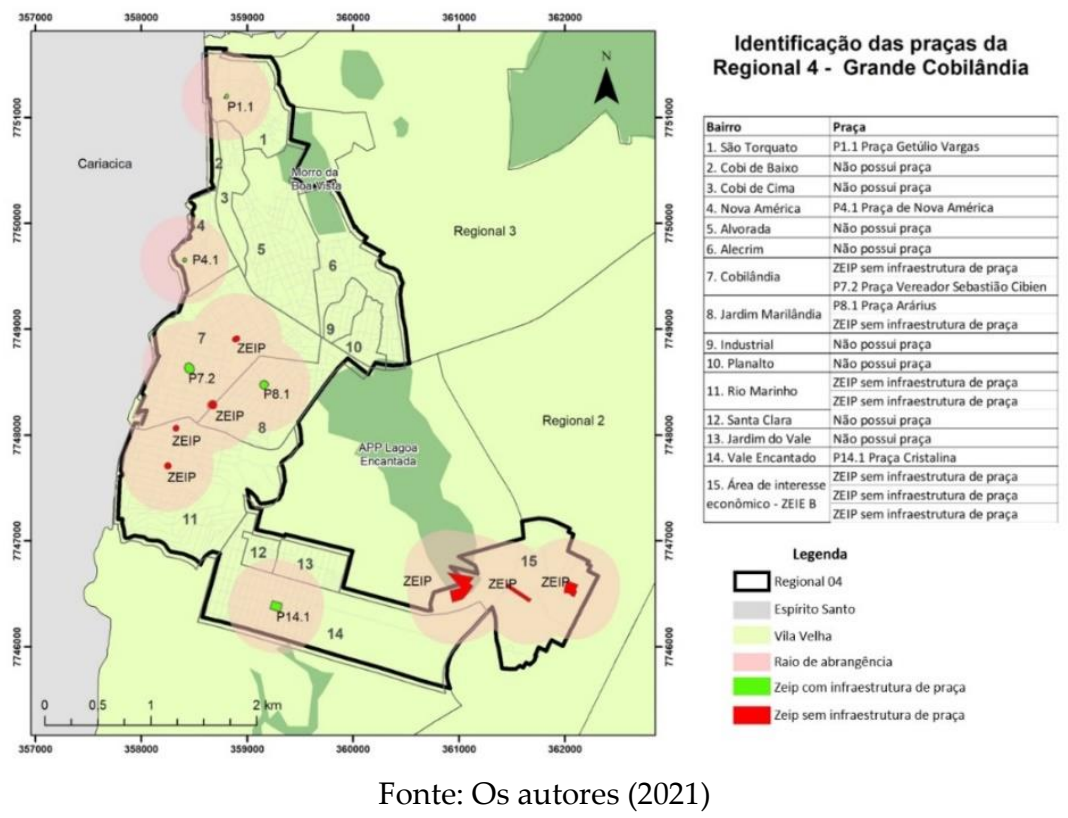


Conforme Plano Diretor Municipal (VILA VELHA, 2018), foram identificadas na Grande Cobilândia 12 (doze) Zonas Especiais de Interesse Público (ZEIPs). Após visitas a cada uma delas, constatou-se que apenas 5 apresentam infraestrutura de praça, as demais encontram-se como vazios urbanos (ZEIPs sem infraestrutura de praça) e, em uma delas, encontra-se um Equipamento Comunitário (Escola Municipal). A Figura 2 ilustra a distribuição espacial das ZEIPS no contexto da Regional, evidenciando as praças em verde, bem como as ZEIPs sem infraestrutura de praça em vermelho.

\section{SOCIABILIDADE, USOS E ATIVIDADES NAS PRAÇAS DA GRANDE COBILÂNDIA}

Após o mapeamento, cada uma das praças foi avaliada conforme parâmetros estabelecidos na ferramenta QualificaURB. A tabela 02 apresenta os resultados por praça de todas as categorias avaliadas. As praças da Grande Cobilândia, em relação à categoria "Sociabilidade, Usos e Atividades", receberam classificação "regular" (pontuação 1,34), assim como a média final da Regional (pontuação 1,36).

Tabela 2 - Avaliação das praças da Grande Cobilândia

\begin{tabular}{|c|c|c|c|c|c|c|}
\hline \multicolumn{7}{|c|}{ Praças da Grande Cobilândia } \\
\hline Categoria & 1.Arárius & $\begin{array}{c}2 . \text { Vale } \\
\text { Encantado }\end{array}$ & $\begin{array}{l}\text { 3. Sebastião } \\
\text { Cibien }\end{array}$ & $\begin{array}{l}\text { 4.Nova } \\
\text { América }\end{array}$ & $\begin{array}{l}\text { 5. Getúlio } \\
\text { Vargas }\end{array}$ & Média final \\
\hline $\begin{array}{l}\text { Proteção e } \\
\text { Segurança }\end{array}$ & 1,17 & 1,17 & 1,5 & 0,75 & 1,25 & 1,17 \\
\hline $\begin{array}{c}\text { Conforto e } \\
\text { Imagem }\end{array}$ & 1,06 & 1,56 & 1,72 & 0,89 & 0,89 & 1,22 \\
\hline $\begin{array}{l}\text { Acessos e } \\
\text { Conexões }\end{array}$ & 1 & 2,5 & 2,5 & 0,75 & 1,75 & 1,7 \\
\hline $\begin{array}{l}\text { Sociabilidade, } \\
\text { usos e atividades }\end{array}$ & 1,09 & 2,25 & 2,59 & 0,53 & 0,25 & 1,34 \\
\hline $\begin{array}{l}\text { PONTU AÇÃO } \\
\text { FINAL PRACCA }\end{array}$ & 1,08 & 1,87 & 2,08 & 0,73 & 1,03 & 1,36 \\
\hline
\end{tabular}

Fonte: Os autores (2021)

O gráfico 1 apresenta a média geral das praças e de cada categoria. Observa-se a discrepância das notas entre as categorias, variando entre as classificações. A categoria "Sociabilidade, Usos e Atividades", por exemplo, ora se apresenta como a categoria mais bem avaliada da praça, ora a pior, com destaque para as praças Vale Encantado (2) e Cibien (3) que receberam conceitos "bom" e "ótimo" nesta categoria.

\section{Gráfico 1 - Avaliação das praças da Grande Cobilândia por categoria}

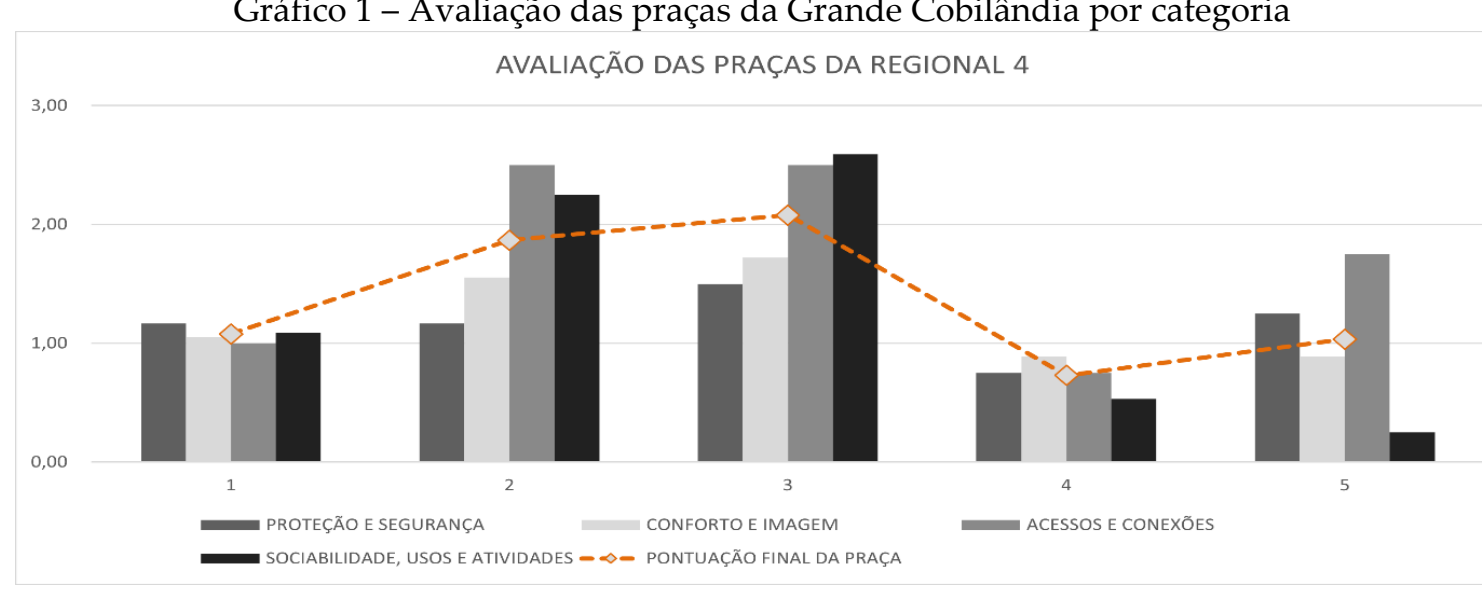

Fonte: Os autores (2021) 
A seguir, na tabela 3, apresentam-se os resultados da categoria "Sociabilidade, Usos e Atividades", e na sequência são apresentados os resultados das análises e suas discussões.

Tabela 3 - resultados da categoria "Sociabilidade, Usos e Atividades"

\begin{tabular}{|c|c|c|c|c|c|c|c|}
\hline & $\begin{array}{l}\text { Bairro em que se localiza a } \\
\text { praça }\end{array}$ & $\begin{array}{c}\text { Jardim } \\
\text { Marilândia }\end{array}$ & $\begin{array}{c}\text { Vale } \\
\text { Encantado }\end{array}$ & Cobilândia & $\begin{array}{c}\text { Nova } \\
\text { América }\end{array}$ & $\begin{array}{c}\text { São } \\
\text { Torquato }\end{array}$ \\
\hline & & Praça analisada & $\begin{array}{l}\text { Praça } \\
\text { Arárius }\end{array}$ & $\begin{array}{l}\text { Praça de } \\
\text { Vale } \\
\text { Encantado }\end{array}$ & $\begin{array}{l}\text { Praça } \\
\text { Sebastião } \\
\text { Cibien }\end{array}$ & $\begin{array}{l}\text { Praça de } \\
\text { Nova } \\
\text { América }\end{array}$ & $\begin{array}{l}\text { Praça } \\
\text { Getúlio } \\
\text { Vargas }\end{array}$ \\
\hline \multirow{9}{*}{ 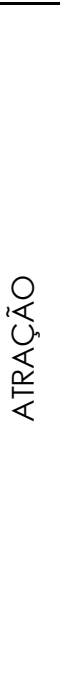 } & \multirow{9}{*}{ 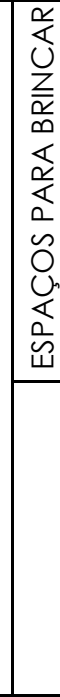 } & Localização & 1,00 & 3,00 & 3,00 & 0,00 & 0,00 \\
\hline & & Material do piso & 1,00 & 1,00 & 1,00 & 0,00 & 0,00 \\
\hline & & Material dos brinquedos & 2,00 & 2,00 & 0,00 & 0,00 & 0,00 \\
\hline & & $\begin{array}{l}\text { Estado de conservação } \\
\text { dos brinquedos }\end{array}$ & 0,00 & 2,00 & 3,00 & 0,00 & 0,00 \\
\hline & & $\begin{array}{l}\text { Soma do critério - Espaço } \\
\text { para brincar }\end{array}$ & 1,00 & 2,00 & 1,75 & 0,00 & 0,00 \\
\hline & & $\begin{array}{l}\text { Equipamentos } \\
\text { comunitários }\end{array}$ & 2,00 & 1,00 & 2,00 & 1,00 & 1,00 \\
\hline & & $\begin{array}{l}\text { Atividades que incluem os } \\
\text { idosos }\end{array}$ & 1,00 & 2,00 & 2,00 & 0,00 & 0,00 \\
\hline & & Uso do solo & 1,00 & 1,00 & 3,00 & 1,00 & 1,00 \\
\hline & & \begin{tabular}{|l|} 
PONTUAÇÃO FINAL DO \\
ATRIBUTO - ATRAÇÃO \\
\end{tabular} & 1,19 & 1,50 & 2,19 & 0,56 & 0,50 \\
\hline \multirow{3}{*}{\multicolumn{2}{|c|}{ 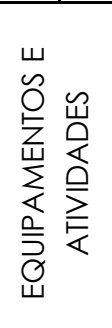 }} & $\begin{array}{l}\text { Equipamentos fixos e } \\
\text { serviços }\end{array}$ & 1,00 & 3,00 & 3,00 & 0,00 & 0,00 \\
\hline & & $\begin{array}{l}\text { Atividades de } \\
\text { apropriações comunitárias }\end{array}$ & 1,00 & 3,00 & 3,00 & 1,00 & 0,00 \\
\hline & & $\begin{array}{l}\text { PONTU AÇÃO FINAL DO } \\
\text { ATRIBUTO - EQUIPAMENTOS } \\
\text { E ATIVIDADES }\end{array}$ & 1,00 & 3,00 & 3,00 & 0,50 & 0,00 \\
\hline \multicolumn{2}{|c|}{ TOTAL } & $\begin{array}{l}\text { SOCIABILIDADE, USOS E } \\
\text { ATIVIDADES }\end{array}$ & 1,06 & 2,17 & 2,31 & 0,35 & 0,17 \\
\hline
\end{tabular}

Fonte: Os autores (2021)

Ao analisar os resultados da Categoria "Sociabilidade, Usos e atividades", no atributo "Atração", duas praças - Getúlio Vargas e Nova América - não são contempladas com espaços para brincar e, portanto, receberam classificação "insuficiente" neste indicador. No indicador "localização dos espaços para brincar", uma praça recebeu classificação "regular" e duas "ótimo", essas últimas com seus espaços para brincar localizados no centro da praça e com cercamento, garantindo segurança para as crianças que utilizam o espaço.

Em "material do piso", as três praças com espaço para brincar receberam classificação "regular", pois possuem playground em areia, material não indicado, uma vez que pode trazer doenças e infecções transmitidas principalmente por animais. Em relação ao "material dos brinquedos", duas praças receberam classificação "bom", com brinquedos predominantes em madeira. Uma praça recebeu classificação "insuficiente", por apresentar brinquedos em metal que além da dureza ao risco de 
acidentes, absorve calor, impossibilitando seu uso. Destaque para a Praça Sebastião Cibien que recebeu classificação "ótimo" na conservação dos brinquedos, indicando que todos estão apropriados ao uso.

Os "equipamentos comunitários" foram contabilizados tanto no interior da praça quanto nas suas imediações. Três praças foram classificadas como "regular", apresentando apenas um equipamento comunitário, e duas delas receberam classificação "bom", com 2 equipamentos comunitários situados na praça e/ou no seu perímetro. Destaque para os equipamentos institucionais religiosos presentes em todas as praças analisadas.

No indicador "Atividades que incluem os idosos" foram verificados mobiliários e atividades presentes na praça que incluem o público idoso, tais como: academia popular, mesa de jogos, campo de bocha e pista para caminhada. Duas praças receberam classificação "insuficiente" por não possuírem nenhuma atividade. Uma delas recebeu classificação "regular" e duas receberam conceito "bom", por apresentarem 2 atividades que incluem idosos.

Em "Uso do solo" foram identificados os usos mais frequentes no entorno da praça. Das 5 praças analisadas, 4 receberam classificação "regular", pois estão situadas em contextos predominantemente residenciais. Somente uma praça recebeu classificação "ótimo" devido ao uso misto do entorno, com funcionamento de comércio diurno e noturno no local. As análises deste indicador evidenciam que o uso no entorno das praças da Grande Cobilândia é predominantemente residencial, prejudicando a vivência e apropriação do espaço da praça, uma vez que menos pessoas circulam e permanecem no local.

No indicador "Equipamentos fixos e serviços", duas praças, representadas na Figura 3, receberam classificação "ótimo", por apresentarem 5 ou mais equipamentos/serviços no interior da praça, tais como: banca de jornais, academia popular, pista de skate, chaveiro e ponto de taxi. Uma praça recebeu classificação "regular" e duas "insuficientes" por apresentarem poucos equipamentos/serviços em seu interior.

Figura 3 - A) Pista de skate na praça Sebastião Cibien.

A) Pista de skate na Praça Sebastião Cibien



B) Academia e playground na Praça Arárius

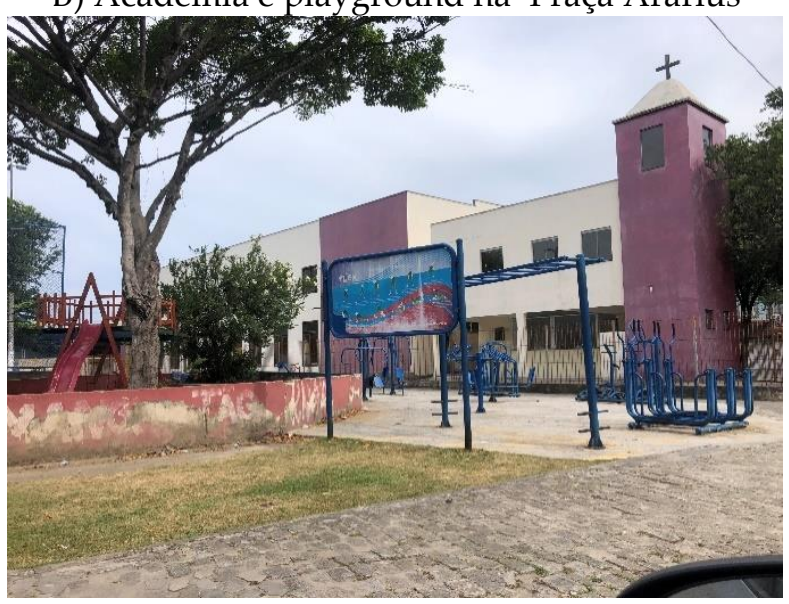

Fonte: Os autores (2021)

Em relação às "apropriações comunitárias", duas praças foram classificadas como "ótimo" e as demais "regular", onde forma observadas apenas 1 tipo de apropriação na praça. Entende-se que as apropriações comunitárias são importantes no ambiente da praça, pois contribuem no sentimento de pertencimento e 
identidade local. São alguns exemplos de apropriações registradas: barraquinhas de comidas, pula-pula, muro com grafismo e atividades esportivas programáticas.

\section{CONCLUSÕES}

Os espaços livres públicos, em especial as praças, são locais propícios para o convívio social e importantes para a manutenção da vida pública urbana. Esses ambientes devem incluir a todos, abrangendo diferentes públicos e oferecendo atividades que tornem a praça atrativa, além de infraestrutura adequada para permitir o uso e a apropriação do espaço. Entretanto, ainda imperam, na maioria das cidades brasileiras, assim como verificado nas praças da Grande Cobilândia, problemas relacionados à manutenção e ao gerenciamento desses espaços, bem como carência de equipamentos e atividades que atraem as pessoas, em especial idosos e crianças, e favoreçam à sociabilidade; atributos essenciais para ressignificar a função social das praças.

As avaliações evidenciam aspectos potenciais, mas também fragilidades, nas praças analisadas, em relação a indicadores de "Sociabilidade, usos e atividades", servindo, assim, de referência para propostas de requalificação e manutenção desses espaços. Uma maior atenção para os espaços de brincar e para as atividades que incluem os idosos mostra-se de extrema importância para qualificar as praças analisadas e contribuir para vitalidade e sociabilidade desses espaços. Ao criar locais de encontro inclusivos e confortáveis, a vida pública é enriquecida e a comunidade local se apropria do espaço público, beneficiando a vida urbana.

\section{REFERÊNCIAS}

BRASIL, ITDP. (2019) Índice de Caminhabilidade Ferramenta, Versão 2.0. Rio de Janeiro.

CONDE, K.; ALVAREZ, C.E.; BRAGANÇA, L. Proposta de critérios e indicadores de avaliação de sustentabilidade urbana para países latino-americanos. In: EuroELECS 2019. III Encontro Latinoamericano Y Europeo sobre Edificaciones y Comunidades Sostenibles. Argentina, Anais... Santa Fe, Argentina, Maio 22-25, 2019 p.1412-1424.

GEHL, Jan. Cidades para pessoas. 2. ed. São Paulo: Perspectiva, 2014.

HEEMANN, Jenifer; SANTIAGO, P. Caiuby. Guia do espaço público para inspirar e transformar. Mountain View (CA), USA, 2015.

IBGE. Instituto Brasileiro de Geografia e Estatística. Censo demográfico 2010. Características da população e dos domicílios: resultados do universo. Rio de Janeiro: IBGE, 2010.

MACEDO et al. Os Sistemas de Espaços Livres e a constituição da esfera pública contemporânea no Brasil. São Paulo: Universidade de São Paulo, 2018.

QUEIROGA, E. F. Sistemas de espaços livres e esfera pública em metrópoles brasileiras. Resgate, v. XIX, n.21, p.25-25, 2011. Disponível em: <www.cmu.unicamp.br/br/seer/index.php /resgate/article/download/.../264>. Acesso em: 16 fev. 2021.

VILA VELHA. Lei complementar nº 65, de 09 de novembro de 2018. Institui a revisão decenal da lei municipal no 4575/2007 que trata do plano diretor municipal no âmbito do município de Vila Velha e dá outras providencias. Vila Velha: Câmara Municipal de Vila Velha. 
WHYTE, William. The Social Life of Small Urban Spaces. 3rd ed., New York: Project for Public Spaces, 2009. 